\title{
ChemComm
}

\section{Sugar-derived organogels as templates for structured, photoluminescent conjugated polymer-inorganic hybrid materials $\uparrow$}

49, 6155

Received 4th May 2013 Accepted 25th May 2013

DOI: $10.1039 /$ c3cc43320j

www.rsc.org/chemcomm

Co-assembly of an inorganic-organic hybrid material through the combination of supramolecular organogel self-assembly, phase partitioning of a conjugated polymer (CP) and transcription of an inorganic oxide leads to a hybrid material with structured domains of organogel, CP and silica within tube and rod microstructures.

Light-harvesting and light-emitting organic-inorganic hybrids based on conjugated polymers (CPs) show considerable promise for photovoltaic $^{1}$ and optoelectronic devices. ${ }^{2}$ Controlled placement of the organic component within the heterogeneous material is challenging due to poor miscibility between the hydrophilic inorganic oxide precursors and the hydrophobic CP. Cooperative physical interactions (e.g. hydrogen bonding, ionic, van de Waals, $\pi-\pi$ stacking) at the interface play a crucial role in determining phase miscibility, ${ }^{1 a, b, 3}$ morphology ${ }^{3}$ and the orientation of individual components. $^{4,5}$ If highly efficient CP-organic-inorganic hybrid devices are to be developed, it is critical that the complex relationship between CP distribution, orientation, interfacial interactions and morphology and macroscopic optoelectronic properties be understood and controlled. ${ }^{1 b, 6 a, b}$

Strategies explored to address phase separation in CP-organicinorganic hybrids include in situ polymerisation, ${ }^{7}$ non-aqueous sol-gel routes, ${ }^{1 a, b, 2 a, 3}$ surfactant templating ${ }^{1 a, b, 2 a, 3,5 b}$ and the use of watersoluble conjugated polyelectrolytes. ${ }^{6 a, c}$ In contrast, phase partitioning has been actively exploited in supramolecular organogels to prepare microstructured inorganic materials. ${ }^{8}$ Low molecular weight organogelators (LMOGs) are organic molecules which, in an appropriate gelation solvent, can self-assemble into a threedimensional anisotropic lattice that contains the entrapped solvent. $^{9-13}$ The resulting matrix can subsequently be employed as a

\footnotetext{
${ }^{a}$ School of Chemistry and Chemical Engineering, Queen's University Belfast, The David Keir Building, Stranmills Road, Belfast, BT9 5AG, UK. E-mail: p.marr@qub.ac.uk; Tel: +44(0)28 90974740

${ }^{b}$ School of Chemistry and CRANN, The University of Dublin, Trinity College, Dublin 2, Ireland. E-mail: raevans@tcd.ie; Tel: +35318964215

$\dagger$ Electronic supplementary information (ESI) available: Experimental details, photographs of materials, SEM images, ${ }^{29} \mathrm{Si}$ MAS-NMR, FTIR spectra, TGA thermograms, surface area, and schematic of transcription process. See DOI: $10.1039 / \mathrm{c} 3 \mathrm{cc} 43320 \mathrm{j}$
}

template for the transcription of nanofibrous materials from an inorganic oxide precursor by sol-gel methods. ${ }^{8,14,15}$ Transcription improves both the thermostability and tensile strength of the gel, or alternatively, removal of the organogel by solvent extraction or sintering, yields the inorganic oxide material, which retains the microstructure of the organic template. Many structures have been obtained, from tubes and $\operatorname{rods}^{9-13}$ to helices ${ }^{8 a}$ and double helices. ${ }^{8 b}$ In systems where the addition of active species to an organogel/silica transcription medium has been achieved, the additive has been shown to partition with the organogel if it is soluble in the organogel/solvent (e.g. metal complexes) and with silica if it is not soluble (e.g. metal nanoparticles). ${ }^{16}$ Given the interest in new routes to $\mathrm{CP}$-organic-inorganic hybrids and CP-based nano/microstructures, ${ }^{17}$ we considered if this approach could be harnessed to prepare $\mathrm{CP}$-inorganic hybrids, in which the relative distribution of the two phases is controlled by phase partitioning.

The sugar-based gelator $\mathbf{1}$ (Fig. 1) has previously been shown to self-assemble into a fibrous supramolecular organogel network in ethanol. ${ }^{11}$ Subsequent transcription with tetraethylorthosilicate (TEOS) yielded silica rods and tubes of micron dimensions. Here we show that the addition of a CP as an additive to the organogel mixture, followed by transcription, results in the formation of uniform $\mathrm{CP}$-silica microtubes that retain the photoluminescence $(\mathrm{PL})$ properties of the parent polymer. Phase partitioning of the hydrophobic $\mathrm{CP}$ at the organogel-silica interface due to low miscibility with both the polar gelation solvent and the sol-gel precursor leads to spatial segregation of the polymer.

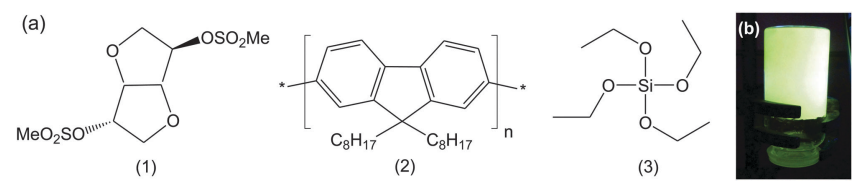

Fig. 1 (a) Chemical structures of the gelator 5-di-O-methanesulfonyl-1,4:3,6dianhydro-D-sorbitol (1), the conjugated polymer PFO (2), and the silica precursor TEOS (3). (b) Inverted PFO-organogel transcribed with silica (PFO-OG-Si) under UV excitation ( $\lambda_{\mathrm{ex}}=366 \mathrm{~nm}$ ). 
Poly(9,9-di- $n$-octylfluorenyl-2,7-diyl) (PFO) was selected as the CP additive, since its optical properties are known to be highly dependent on the phase morphology. ${ }^{18}$ For example, the incorporation of PFO into ionic liquid templated silica ionogels leads to cooperative self-assembly of the organic-inorganic components, driving the formation of the PFO $\beta$-phase. ${ }^{4}$ Moreover, poly(fluorenes) can themselves self-assemble into organogels in which supramolecular organisation of the polymer chains in the gel can modify the optoelectronic properties. ${ }^{19}$

Four samples were investigated: organogel containing PFO (PFO-OG), organogel containing PFO transcribed with silica (PFO-OG-Si) and two blank samples, pure organogel (OG) and organogel transcribed with silica (OG-Si) (for synthetic details see ESI $\dagger$ ). The resultant PFO-OG was orange in colour and exhibited yellow-green PL upon excitation at $366 \mathrm{~nm}$ (Fig. S1, ESI $\dagger$ ). PFO-OG-Si, similarly exhibited yellow-green PL and was stable to inversion (Fig. 1b).

The structural features of the transcribed organogel superstructure were examined using scanning electron microscopy (SEM). Blank transcribed silica tubes (OG-Si) were shown to comprise of both rods and hollow tubes (Fig. 2a), ranging from $10-60 \mu \mathrm{m}$ in length $($ mean $=32.5 \pm 11.8 \mu \mathrm{m})$ and $0.4-1.6 \mu \mathrm{m}$ (mean = $0.8 \pm 0.3 \mu \mathrm{m}$ ) in width, with random orientation. PFO-OG-Si tubes exhibit similar mean dimensions (length $=34.5 \pm 26.2 \mu \mathrm{m}$, width $=$ $0.8 \pm 0.4 \mu \mathrm{m}$, aspect ratio $\sim 40$ ) (Fig. 2b); however the sample was more polydisperse and some tubes were able to grow to considerable length without fracture (up to $83.3 \mu \mathrm{m}$ ). The surface morphology of PFO-OG-Si tubes is also smoother (Fig. 2b). Notably, fracturing during preparation of SEM samples was less significant for PFOOG-Si, suggesting a greater tensile strength than the OG-Si sample. The addition of saturated polymers (e.g. butyl rubber) has previously been shown to enhance the tensile strength of organogels. ${ }^{20}$

${ }^{29} \mathrm{Si}$ MAS NMR indicates the presence of predominantly $\mathrm{Q}^{3}$ $\left((\equiv \mathrm{SiO})_{3} \mathrm{SiOH},-102 \mathrm{ppm}\right)$ and $\mathrm{Q}^{4}\left((\equiv \mathrm{SiO})_{4} \mathrm{Si},-111 \mathrm{ppm}\right)$ silicon species in PFO-OG-Si (Fig. S5, ESI $\dagger$ ). The degree of condensation, $C$, was determined to be $92 \%$, which is consistent with a highly condensed $\mathrm{SiO}_{2}$ network. Thermogravimetric analysis was used to determine the wt\% organic/inorganic content in PFO-OG-Si (Fig. S6, ESI $\dagger$ ). The pure organogel OG displays a primary decomposition step corresponding to an $89.9 \%$ weight-loss centred at $273{ }^{\circ} \mathrm{C}$, followed by a secondary oxidation process $\left(300-600{ }^{\circ} \mathrm{C}, 9.2 \%\right)$. PFO undergoes complete $(100 \%)$ thermal degradation between $300-600{ }^{\circ} \mathrm{C}^{21}$
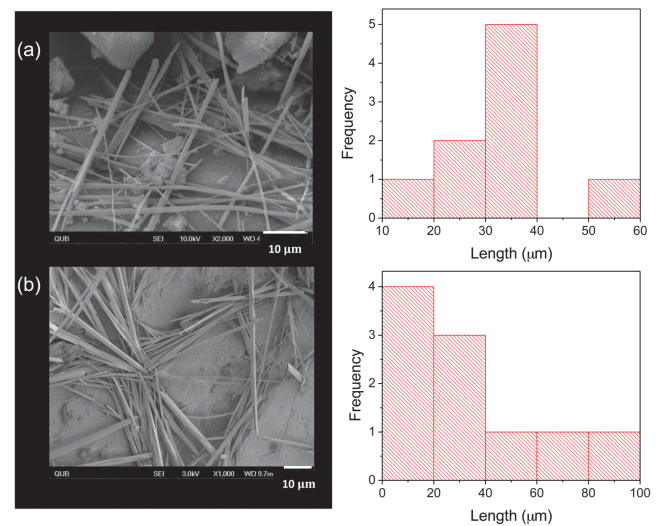

Fig. 2 SEM images and corresponding length distributions of (a) OG-Si and (b) PFO-OG-Si tubes.
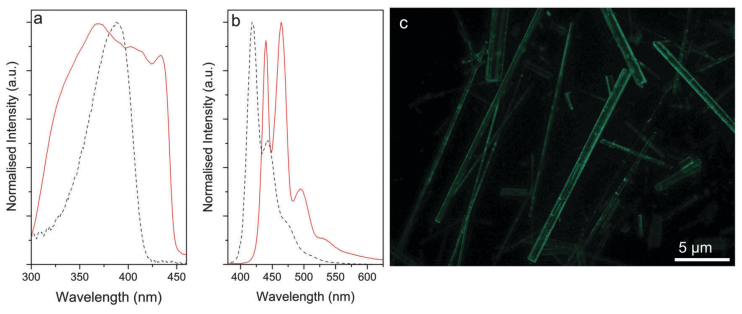

Fig. 3 (a) Absorption-excitation and (b) PL spectra for PFO in $\mathrm{CHCl}_{3}$ (dashed line) and PFO-OG-Si (solid line) ( $\lambda_{\text {ex }}=370 \mathrm{~nm}$ ). (c) FM image of PFO-OG-Si ( $\lambda_{\mathrm{ex}}=360-370 \mathrm{~nm}, 10 \times$ magnification).

On this basis, PFO-OG is estimated to contain $\sim 78 \mathrm{wt} \%$ OG and $\sim 22 \mathrm{wt} \%$ PFO. OG-Si and PFO-OG-Si undergo a complex multistep degradation process, suggesting that the thermal stability of the organic component is improved by the silica tubes. As expected, these samples do not undergo complete thermal degradation under the conditions employed, with the residue at $800{ }^{\circ} \mathrm{C}$ being attributed to siliceous species ( $72 \mathrm{wt} \%$ and $56 \mathrm{wt} \%$, respectively). The results indicate that a significant organic component is retained in the sample following filtration, which is confirmed by the FTIR spectrum of PFO-OG-Si (Fig. S7, ESI + ). In addition to spectral bands attributed to $\nu_{\mathrm{Si}-\mathrm{O}}$ stretching modes $\left(1063,1166 \mathrm{~cm}^{-1}\right)$, weak bands at $1340 \mathrm{~cm}^{-1}$ and $1757 \mathrm{~cm}^{-1}$, characteristic of OG were also observed. The absence of the $\nu_{\mathrm{Si}-\mathrm{OH}}$ stretching mode at $3400 \mathrm{~cm}^{-1}$ also confirms the presence of a condensed siliceous network.

Fig. 3 shows the UV/Vis absorption, PL and excitation spectra for PFO in chloroform and PFO-OG-Si tubes in the solid-state. In $\mathrm{CHCl}_{3}$, the absorption and PL spectra are characteristic of PFO in its disordered $\alpha$-phase, ${ }^{18}$ exhibiting a broad absorption band centred at $c a .390 \mathrm{~nm}$ and a structured emission band, with peaks at 417,442 and $471 \mathrm{~nm}$ corresponding to $0-0,0-1$ and $0-2$ vibronic transitions, respectively. In comparison, the PL spectrum of PFO-OG-Si is red-shifted (439 nm $(0-0), 464 \mathrm{~nm}(0-1)$ and $493 \mathrm{~nm}(0-2))$ and the relative intensities of the $(0-0)$ and $(0-1)$ vibronic bands are inverted. The corresponding excitation spectrum reveals a broad band between $300-450 \mathrm{~nm}$, with maxima at $\sim 370$ and $\sim 430 \mathrm{~nm}$. PFO in the $\beta$-phase exhibits a characteristic absorption peak at $435 \mathrm{~nm}$ and vibrational transitions at 446, 473, and $500 \mathrm{~nm}$ in the PL spectrum. ${ }^{4,18}$ While we cannot exclude the possibility of some $\beta$-phase formation, the significant overlap of the excitation/PL spectra, the smaller red-shift in the PL spectrum and the reduced intensity of the $0-0$ vibronic band observed for PFO-OG-Si are more indicative of self-absorption. The occurrence of self-absorption implies that the PFO chains are located in close vicinity in the tubes and exist as microscopically segregated PFO domains, as reported previously for poly[9,9-bis(2-ethylhexyl)-fluorene] in saturated polymer blends. ${ }^{22}$ Fig. 3c shows a fluorescence microscopy (FM) image of PFO-OG-Si deposited on a glass substrate. Discrete, well-dispersed microrods are apparent, with uniform PL observed across the full length of the tubes. In contrast, PFO-OG exhibits a heterogeneous dispersion of tube and belt-like structures, with some evidence of bundling (Fig. S8, ESI $\dagger$ ). The observed PL appears to be concentrated along the rod/tube edges, which may possibly be due to aggregation of the PFO within a confined spatial region, enhanced PL from emissive surface trap sites, or indeed a combination of both effects.

On the basis of the structural characterisation, we propose that CP-OG-silica microtubes are assembled as follows: the organogelator 


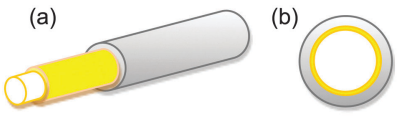

(c)

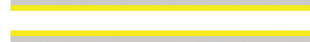

Scheme 1 Schematic representation of the proposed structure of a PFOcontaining organogel transcribed with silica: self-assembled organic fibre or empty tube (white), PFO (yellow), silica (grey). (a) 3D, (b) cross-section and (c) longitudinal cross section of the hybrid material.

and solvent are first heated to produce a homogeneous solution. The CP (PFO) solution is added. Upon cooling, self-assembly of the organogel occurs creating a fibrous rod-like structure. Addition of the silica precursor (TEOS) and a suitable catalyst on cooling facilitates transcription (coating of a inorganic sheath onto the surface of an organogel network), which proceeds first by sol deposition, followed by condensation and growth of the silica network. Washing and filtering partially removes the template yielding hollow tubes; where this procedure is insufficient the OG is retained within the core and they appear as rods. PFO is expected to be immiscible with both the organogel and the hydrophilic sol gel phase. Ethanol is employed as the gelation solvent, which, on the basis of their Hildebrand solubility parameters, is expected to be a poor solvent for PFO $(\delta=9.1-9.3$ and $\delta=12.7$ for $\mathrm{PFO}^{23}$ and $\mathrm{EtOH},{ }^{24}$ respectively). PFO is thus expected to exist in an aggregated $\alpha$-phase (as confirmed by the PL data). ${ }^{29}$ Si MAS NMR indicates that the silica network is highly condensed, inferring that the PFO is not partitioned within this phase. We propose, that PFO preferentially segregates at the organogel-silica phase interface, (Scheme 1) which is consistent with the observed PL self-absorption and the smooth surface morphology.

In summary, we have demonstrated the targeted formation of PFO-silica hybrid microtubes using a sugar-derived organogel template, in which the distribution of the organic CP and inorganic silica components was controlled via selective partitioning of the $\mathrm{CP}$ at the organogel/silica interface. This mild synthetic approach to CP-organic-inorganic hybrids is expected to be general and extendable to other CPs, enabling the development of CP-inorganic hybrids whose composition and optoelectronic properties are targeted towards an end application. Moreover by changing the gelation solvent it should be possible to modulate the phase partitioning of the CP phase (e.g. from the interface to the organic phase), thereby providing a direct means of controlling the CP distribution within these materials. Mesostructured CP-inorganic oxides have already demonstrated their promise in optoelectronic and photovoltaic device applications. ${ }^{1,2}$ Moreover one-dimensional CP nanostructures are often touted as potential building blocks for future optoelectronic nanoscale devices. ${ }^{17}$ Our mild synthetic approach to $\mathrm{CP}$-organic-inorganic hybrid may provide a means of bridging these research fields, leading to the design of more efficient light-emitting and light-harvesting scaffolds.

Solid-state NMR spectra were obtained at the EPSRC UK National Solid-state NMR Service at Durham University.

\section{Notes and references}

1 (a) S. Neyshtadt, M. Kalina and G. L. Frey, Adv. Mater., 2008, 20, 2541; (b) S. Neyshtadt, J. P. Jahnke, R. J. Messinger, A. Rawal,
T. S. Peretz, D. Huppert, B. F. Chmelka and G. L. Frey, J. Am. Chem. Soc., 2011, 133, 10119; (c) T. Xu and Q. Qiao, Energy Environ. Sci., 2011, 4, 2700; (d) L. Zhao and Z. Lin, Adv. Mater., 2012, 24, 4346.

2 (a) E. Dovgolevsky, S. Kirmayer, E. Lakin, Y. Yang, C. J. Brinker and G. L. Frey, J. Mater. Chem., 2008, 18, 423; (b) A. N. Aleshin, E. L. Alexandrova and I. P Shcherbakov, J. Phys. D: Appl. Phys., 2009, 42, 105108.

3 S. Kirmayer, E. Dovgolevsky, M. Kalina, E. Lakin, S. Cadars, J. D. Epping, A. Fernández-Arteaga, C. Rodríguez-Abreu, B. F. Chmelka and G. L. Frey, Chem. Mater., 2008, 20, 3745.

4 R. C. Evans and P. C. Marr, Chem. Commun., 2012, 48, 3742.

5 (a) T. Q. Nguyen, J.-J. Wu, B. J. Schwartz and S. H. Tolbert, Science, 2000, 288, 652; (b) Y. Yang, Y. Lu, M. Lu, J. Huang, R. Haddad, G. Xomeritakis, N. Liu, A. P. Malanoski, D. Sturmayr, H. Fan, D. Y. Sasaki, R. A. Assink, J. A. Shellnutt, F. Swol, G. P. Lopez, A. R. Burns and C. J. Brinker, J. Am. Chem. Soc., 2003, 125, 1269; (c) T.-Q. Nguyen, J. Wu, S. H. Tolbert and B. J. Schwartz, Adv. Mater., 2001, 13, 609.

6 (a) R. C. Evans, A. G. Macedo, S. Pradhan, U. Scherf, L. D. Carlos and H. D. Burrows, Adv. Mater., 2010, 22, 3032; (b) R. C. Evans, J. Mater. Chem. C, 2013, DOI: 10.1039/C3TC30543K; (c) S. Clement, A. Tizit, S. Desbief, A. Mehdi, J. D. Winter, P. Gerbaux, R. Lazzaroni and B. Boury, J. Mater. Chem., 2011, 21, 2733.

7 (a) T. Xu, M. Yan, J. D. Hoefelmeyer and Q. Qiao, RSC Adv., 2012, 2, 854; (b) E. Z. Faraggi, Y. Sorek, O. Levi, Y. Avny, D. Davidov, R. Neumann and R. Reisfeld, Adv. Mater., 1996, 8, 833; (c) B. LutherDavies, M. Samoc and M. Woodruff, Chem. Mater., 1996, 8, 2586.

8 (a) K. J. C. van Bommel, A. Friggeri and S. Shinkai, Angew. Chem., Int. Ed., 2003, 42, 980-999; (b) K. Sugiyasu, S.-I. Tamaru, M. Takeuchi, D. Berthier, I. Huc, R. Oda and S. Shinkai, Chem. Commun., 2002, 1212.

9 (a) M. Llusar and C. Sanchez, Chem. Mater., 2008, 20, 782; (b) P. Terech and R. G. Weiss, Chem. Rev., 1997, 97, 3133-3159; (c) D. J. Abdallah and R. G. Weiss, Adv. Mater., 2000, 12, 1237-1247; (d) N. M. Sangeetha and U. Maitra, Chem. Soc. Rev., 2005, 34, 821-836; (e) P. Dastidar, Chem. Soc. Rev., 2008, 37, 2699.

10 (a) Molecular Gel Materials with Self-Assembled Fibrillar Networks, ed. P. Terech and R. G. Weiss, Springer, Dordrecht, Netherlands, 2006; (b) J. W. Steed, Chem. Commun., 2011, 47, 1379.

11 S. J. Craythorne, C. L. Pollock, A. J. Blake, M. Nieuwenhuyzen, A. C. Marr and P. C. Marr, New J. Chem., 2009, 33, 479.

12 A. Vintiloiu and J. C. Leroux, J. Controlled Release, 2008, 125, 179.

13 (a) J. Reichwagen, H. Hopf, A. Del Guerzo, C. Belin, J.-P. Desvergne and H. Bouas-Laurent, Org. Lett., 2005, 7, 971; (b) N. M. Sangeetha, S. Bhat, G. Raffy, C. Belin, A. Loppinet-Serani, C. Aymonier, P. Terech, U. Maitra, J. P. Desvergne and A. Del Guerzo, Chem. Mater., 2009, 21, 3424.

14 C. J. Brinker and G. W. Scherer, Sol-Gel Science: the Physics and Chemistry of Sol-Gel Processing, Academic Press, 1990.

15 O. Gronwold, E. Snip and S. Shinkai, Curr. Opin. Colloid Interface Sci., 2002, 7, 148.

16 A. C. Marr and P. C. Marr, Dalton Trans., 2011, 40, 20.

17 Examples: (a) A. Ajayaghosh and V. K. Praveen, Acc. Chem. Res., 2007, 40, 644; (b) J. B. Yu, C. F. Wu, S. P. Sahu, L. P. Fernando, C. Szymanski and J. McNeill, J. Am. Chem. Soc., 2009, 131, 18410; (c) S. Moynihan, D. Iacopino, D. O'Carroll, H. Doyle, D. A. Tanner and G. Redmond, Adv. Mater, 2007, 19, 2474.

18 (a) A. P. Monkman, C. Rothe, S. King and F. Dias, Adv. Polym. Sci., 2008, 212, 187; (b) B. P. Lyons, K. S. Wong and A. P. Monkman, J. Chem. Phys., 2003, 118, 4707.

19 (a) J. Lin, Z. Yu, W. Zhu, G. Xing, Z. Lin, S. Yang, L. Xie, C. Niu and W. Huang, Polym. Chem., 2013, 4, 477; (b) J.-H. Chen, C.-S. Chang, Y.-X. Chang, C.-Y. Chen, H.-L. Chen and S.-A. Chen, Macromolecules, 2009, 42, 1306; (c) Z.-Q. Lin, N.-E. Shi, Y.-B. Li, L. Zhang, J.-Y. Lin, J.-F. Zhao, C. Wang, L.-H. Xie and W. Huang, J. Phys. Chem. C, 2011, $115,4418$.

20 D. Ceylan and O. Okay, Macromolecules, 2007, 40, 24.

21 C.-H. Chou, S.-L. Hsu, K. Dinakaran, M.-Y. Chiu and K.-H. Wei, Macromolecules, 2005, 38, 745.

22 (a) C.-C. Kuo, C.-H. Lin and W.-C. Chen, Macromolecules, 2007, 40, 6959; (b) M. Knaapila, H. L. Vaughan, T. P. A. Hase, R. C. Evans, R. Stepanyan, M. Torkkeli, H. D. Burrows, U. Scherf and A. P. Monkman, Macromolecules, 2010, 43, 299.

23 M. Grell, D. D. C. Bradley, X. Long, T. Chamberlain, M. Inbasekaran, E. P. Woo and M. Soliman, Acta Polym., 1998, 49, 439.

24 C. E. Carraher Jr, Introduction to Polymer Chemistry, CRC Press, Boca Raton, 3rd edn, 2013. 